\title{
Review
}

Journal of Innate

Immunity
J Innate Immun 2011;3:289-297

DOI: $\underline{10.1159 / 000324143}$
Received: November 8, 2010

Accepted after revision: January 10, 2011

Published online: March 23, 2011

\section{The Role of Natural Killer Cells in the Defense against Listeria monocytogenes Lessons from a Rat Model}

\author{
Christian Naper $^{\mathrm{b}}$ Hamid Shegarfi ${ }^{\mathrm{a}} \quad$ Marit Inngjerdingen $^{\mathrm{b}} \quad$ Bent Rolstad $^{\mathrm{a}}$ \\ a Department of Anatomy, Institute of Basic Medical Sciences, University of Oslo, and ${ }^{\mathrm{b}}$ Institute of Immunology, \\ Oslo University Hospital, Rikshospitalet, Oslo, Norway
}

\section{Key Words}

Natural killer cells $\cdot$ Major histocompatibility complex class I - Ly49 receptors $\cdot$ Listeria monocytogenes $\cdot$ Infection • Rat

\begin{abstract}
Ly49 receptors in rodents, like killer cell immunoglobulin-like receptors in humans, regulate natural killer (NK) cell activity. Although inhibitory Ly49 receptors clearly recognize classical major histocompatibility complex class I (MHC-I) molecules, the role for the activating Ly 49 receptors has been less well understood. Here, we discuss recent data from a rat model for listeriosis. Rats depleted of NK cells, or more specifically the Ly49 receptor-bearing cells, showed increased bacterial loads in their spleen. Athymic nude rats with no functional T cells but increased numbers of Ly49-expressing NK cells were more resistant to infection, indicating a central role of NK cells in early immune defense against Listeria in this species. Listeria infection of macrophages or enteric epithelial cells led to upregulation of MHC-I, including nonclassical (Ib) molecules not regularly recognized by $T$ cells. We have shown that activating Ly49 receptors are more efficiently stimulated when binding to upregulated class lb antigens on infected cells. From this we postulate that activat-
\end{abstract}

ing Ly49 receptors may have a sentinel function in the early immune response against Listeria in detecting diseased cells 'flagged' by increased MHC-lb expression.

Copyright $\odot 2011$ S. Karger AG, Basel

\section{The Bacterium}

Listeria monocytogenes is a facultative intracellular bacterium that was independently discovered in 1926 by a research group in the United Kingdom and nearly concurrently by a group in South Africa [1]. Listeria is a rodshaped Gram-positive bacterium that has the ability to transform from a saprophytic to an intracellular life, and therefore, can live in e.g. soil but also as an intracellular parasite in several animal species [2]. The genome size of L. monocytogenes is approximately 3 million base pairs, including 2,853 protein-coding genes - amongst them 133 surface proteins, 68 lipoproteins and 11 hydrophobic tail proteins $[1,3]$. Listeria is able to proliferate in temperatures ranging from 4 to $37^{\circ} \mathrm{C}$ and it encodes thermoregulated virulence genes. These genes are controlled by the transcriptional activator PrfA working optimally at $37^{\circ} \mathrm{C}$, which is a key factor for the transition from the saprophytic to the intracellular stage [2].

\section{KARGER}

Fax +4161306 1234

E-Mail karger@karger.ch

www.karger.com (c) 2011 S. Karger AG, Basel

$1662-811 X / 11 / 0033-0289 \$ 38.00 / 0$

Accessible online at:

www.karger.com/jin
Dr. Bent Rolstad

Department of Anatomy, Institute of Basic Medical Sciences

University of Oslo

NO-0316 Oslo (Norway)

Tel. +47 2285 1212, E-Mail bent.rolstad@medisin.uio.no 


\section{Listeria Infections in Humans}

Listeria is widespread in nature, but seldom causes clinical infections in healthy individuals apart from occasional disease outbreaks. Although Listeria infection is rare (7 per 1,000,000 healthy people each year), the overall mortality rate of systemic infection is high (approximately 25\%) compared to other pathogens such as Salmonella $(<1 \%)[3,4]$. Listeria may cause sepsis and spread to the nervous system causing cranial nerve palsies, encephalitis, abscesses or meningitis. Since Listeria infections are relatively rare in humans, it represents little threat to the population as a whole. However, immunocompromized individuals such as transplanted patients or persons with AIDS are particularly vulnerable. Furthermore, pregnant women are at risk, since Listeria can infect fetuses, particularly in the third trimester, by penetrating the endothelial layer of the placenta. This may lead to premature labor, stillbirth, abortions and neonatal infections [5].

Since there are no vaccines against Listeria, knowledge about the mode of infection, virulence factors, spread of the bacterium and putative immune responses against it are important factors when considering preventive measurements for patients at risk. Humans are often exposed to Listeria through contaminated food products, such as unpasteurized dairy products, incompletely cooked meats or vegetables contaminated from soil. Also, animals may be carriers of Listeria without having symptoms of infection $[1,6]$. Since clinical infection usually is sporadic rather than epidemic in humans, it is difficult to identify immunogenetic factors that predispose to resistance or susceptibility. The strategies Listeria use to infect host cells have largely been identified in animal models. Below, we describe some mechanisms that Listeria uses to evade host defense mechanisms, bearing in mind that there may be considerable species variations.

\section{Mechanisms by Which Listeria Infects Cells and Evades the Immune System}

Listeria is usually eliminated by the immune system in the gut. The cells and secreted substances that contribute to this defense are not well described, except that $\mathrm{CD} 8^{+} \mathrm{T}$ cells in the epithelium may play a role [1]. However, bacteria that escape these initial defense mechanisms may give rise to serious systemic infections. Listeria primarily infects macrophages $(\mathrm{M} \phi)$, dendritic cells (DCs), hepatocytes and intestinal epithelial cells, but fibroblasts, endo- thelial cells, neurons and even lymphocytes including natural killer (NK) cells may be susceptible $[7,8]$. Listeria is taken up by $\mathrm{M} \phi$ by binding to polysaccharide receptors or type I M $\phi$ scavenger receptors $[4,6]$. Uptake in intestinal epithelial cells is dependent on interactions between Listeria surface protein internalin A and epithelial cadherin (E-cadherin) [1]. After internalization, Listeria must be able to escape from the vacuole/phagosome before fusion with lysosomes in order to survive. This key process is dependent on listeriolysin $\mathrm{O}$, an enzyme that lyses the endosomal membrane and is a central virulence factor for Listeria [8]. The escape from phagosomes is enhanced by bacterial phospholipase C [9]. Listeriolysin O also induces apoptosis of activated lymphocytes. Once in the cytosol, Listeria uses the cellular machinery to move around. It induces directed polymerization of actin by the actin assembly-inducing protein, thus pushing itself through the cytoplasm. In the same manner, the bacterium moves from cell to cell covered by a layer of the host cell membrane protecting it from extracellular immune defense mechanisms such as acute phase proteins, complement factors and antibodies. The innate and adaptive immune mechanisms that protect infected individuals from disease are incompletely understood [10]. Especially, the role of Listeria-derived peptides has been poorly investigated in humans. Several animal experimental models have been developed to study Listeria infections. The mouse has been widely utilized, although there are several fundamental differences between rodents and man in how the bacterium is internalized in the intestine and the mode of spread to various organs [5]. Therefore, extrapolation from animal models to man should be done with caution.

\section{Immune Responses to Listeria in Mice}

The mouse has been used as a model organism for studying interactions between Listeria and the immune system $[1,11]$. The first evidence that cellular immune responses were instrumental in resistance to Listeria came from adoptive transfer of lymphocytes from infected to naive mice $[12,13]$. Interestingly, the ability of Listeria to induce potent innate and adaptive immune responses has been exploited in cancer immunotherapy [14, $15]$.

Innate immune responses are rapidly triggered upon Listeria infections and are essential for host survival [1, 16]. Within the first $24 \mathrm{~h}$ after infection, neutrophils gather at the infection site $[17,18]$. They migrate from the bone 
marrow into the liver and spleen, which are the primary sites of Listeria growth upon systemic infections. Here, the neutrophils contribute to bacterial killing and destruction of infected cells. Neutrophil depletion studies have shown that these cells are important in the earliest phase of the infection $[1,19]$. In the spleen, infection of $\mathrm{M} \phi$ in the marginal zones induces secretion of the monocyte chemotactic protein 1 , which in turn induces a CCR2dependent recruitment of specialized monocytes from the bone marrow. These monocytes differentiate into tumor necrosis factor (TNF)- $\alpha$ and inducible nitric oxide synthase-producing DCs, called 'TipDCs' [20, 21]. Mice deficient in CCR2 are more susceptible to Listeria growth in the spleen which may be the result of a lack of TipDCs in the spleen [20-22]. NK cells represent an important source of interferon (IFN)- $\gamma$ production at infectious loci containing infected $\mathrm{M} \phi$ and TipDCs [23]. The exact mechanism by which NK cells are recruited here is unclear, but may partly result from a CCR5-dependent response to $\mathrm{M} \phi$ inflammatory proteins $1 \alpha$ and $1 \beta$ secreted by activated $M \phi$ [23]. It is unclear whether the NK cells derive from local spleen cells, or are recruited from the bone marrow [24]. Although IFN- $\gamma$ production by NK cells contributes to the innate immune resistance, memory cytotoxic T lymphocytes (CTLs) seem to be the dominant IFN- $\gamma$ producers in mice [25]. Recent studies have shown the importance of antigen-presenting cells in controlling both the innate and adaptive immune responses to Listeria $[23,26]$. Although innate immune responses may limit the infection as shown in severely combined immunodeficient mice, it is clear that long-term sterilizing immunity is dependent on an intact adaptive immune system [27].

M $\phi$ are activated at the site of infection, and this is necessary for their ability to kill Listeria. How activated M $\phi$ kill Listeria is not entirely clear, but the generation of reactive nitrogen and oxygen metabolites is thought to be central [11]. M $\phi$ produce TNF- $\alpha$ and interleukin (IL)-12 necessary for NK cell activation and IFN- $\gamma$ secretion. In addition, activated DCs produce IL-12 and IL-18 that may also stimulate NK cells [28]. IFN- $\gamma$ mediates multiple effects including activation of M申. Its importance is evident in mice lacking the IFN- $\gamma$ receptor, which are highly susceptible to Listeria infection [29]. Conversely, type I IFNs, important in the viral defense, have been reported to impair antibacterial responses [30-32], although recent experiments have shown that type I IFNs may have protective effects in the absence of MyD88-mediated signaling [33]. Direct antibacterial activity by NK cells has also been shown, although the mechanisms are unclear
$[34,35]$. TNF- $\alpha$ is another cytokine essential for primary resistance to Listeria [23].

DCs and M $\phi$ present Listeria peptides to T cells [17]. DCs are required for priming of naive Listeria-specific $\mathrm{CD}^{+} \mathrm{T}$ cells [14], an ability which $\mathrm{M} \phi$ do not have [36]. CTL responses against cells presenting Listeria peptides on either MHC-Ia or MHC-Ib molecules contribute to resistance to this pathogen [1]. Class Ia molecules can present a range of Listeria-derived peptides generated by proteasome degradation of Listeria-derived proteins in the cytosol [1]. CTL responses to listeriolysin $\mathrm{O}$ and p60 peptides have been well characterized. Of the class $\mathrm{Ib}$ molecules, particular emphasis has been put on H2-M3. This MHC-Ib molecule promiscuously presents a range of formylated peptides from bacteria to CTLs and may identify cells infected with a wide range of bacteria that are dependent on formylated methionin for protein synthesis [1]. These two modes of CTL recognition may be temporally separated. The class Ib response may precede the class Ia response and has more of the feature of a nonadaptive immune response with little immunological memory, while the class-Ia-restricted CTLs predominate in the secondary memory response to Listeria and bring along sterilizing immunity [1]. However, these mechanisms do not account for all resistance connected to MHC-I presentation of Listeria peptides, since MHCIa-deficient mice are able to mount protective immune responses to formyltransferase-deficient Listeria strains $[37,38]$. However, the MHC-Ib molecules conferring this resistance have not been identified. In the spirit of the next section we would suggest that these class $\mathrm{Ib}$ molecules might be ligands for MHC-I receptors on NK cells. Furthermore, there is evidence that most CTLs recruited to the site of infection are not specific for Listeria peptides. However, they may produce large amounts of IFN- $\gamma$ important for the clearance of the bacterium [39, 40].

NK cells produce IFN- $\gamma$ and may be important for the early defense against Listeria [41]. However, the role of NK cells has been subject to controversies, as both beneficial and detrimental effects of NK cells have been observed. Mice deficient in DAP12, necessary for signaling through many activating receptors on NK and myeloid cells $[42,43]$, and mice deficient in type I IFN production important for activation of NK cells [32] were more resistant to Listeria. Furthermore, NK1.1 $1^{+}$cells, being mostly NK cells, have been shown to impede resistance to Listeria [44]. Finally, NK cells may produce the anti-inflammatory cytokine IL-10 during systemic Listeria infections $[45,46]$. These controversies may depend on the ex- 


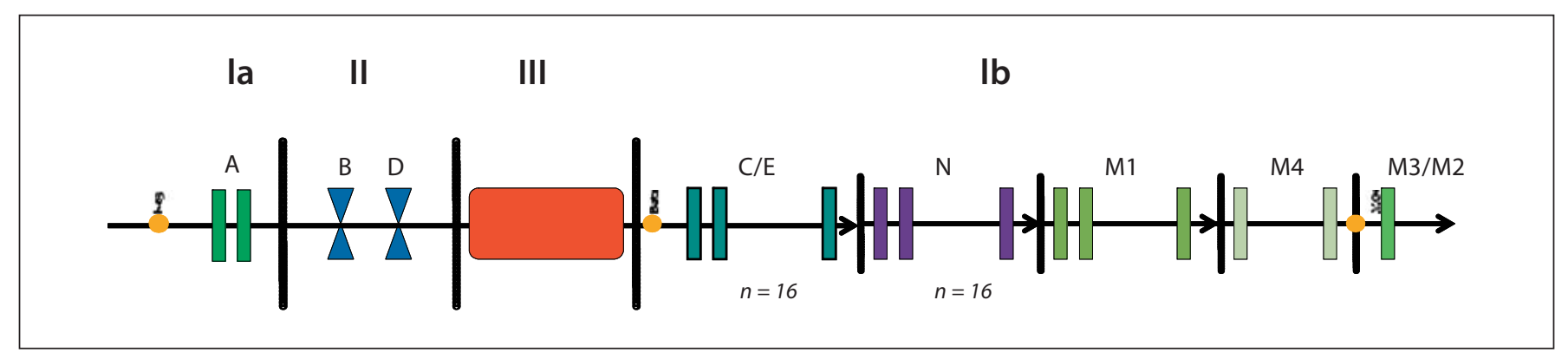

Fig. 1. A schematic view of the rat MHC (RT1). Ia = Classical class I genes; Ib = nonclassical class I genes. Note the similarities with mouse $\mathrm{H} 2$ (not shown) in the overall organization of the MHC, except that $\mathrm{H} 2 \mathrm{D} / \mathrm{L}$ genes are lacking in the rat. The class Ia region may contain 1,2 or 3 loci depending on the rat strain. The $\mathrm{C} / \mathrm{E}$ region also varies greatly in gene content between rat strains.

perimental systems studied, and Listeria models in other species may help understand these discrepancies.

In rodent infection models, Listeria is usually given intravenously since rodents cannot easily be infected via the oral route. Even with high doses of bacteria, oral infection seldom leads to lethality [5]. It has been discovered that mouse E-cadherin is unable to interact with internalin A due to the amino acid [47] at position 16 in E-cadherin (glutamic acid in mice, proline in humans). This probably explains why rodents might be carriers of the bacteria without getting systemic infections.

\section{Listeria Models in the Rat}

Early studies in the rat showed that $\mathrm{T}$ cells from Listeria-infected rats conferred resistance when transferred to naive hosts, and this resistance showed MHC restriction [48]. However, until recently, the role of the innate immune system has been given little attention.

We caught an interest in the role of NK cells in resistance to Listeria since infection of M $\phi$ and intestinal epithelial cells led to an increased MHC-I expression, especially of nonclassical class I, that could conceivably influence NK cell recognition. We have previously shown that some nonclassical MHC-I molecules are ligands for NK cell receptors. These molecules are encoded by a string of genes telomeric of the class II/III region (fig. 1) [49, 50]. Based on immunogenetic and functional studies, the ligands for several activating and inhibitory Ly 49 receptors have been mapped to the proximal part of this nonclassical class I region, termed ' $R T 1-C E$ ' (fig. 1) [51-55]. Rat as opposed to mouse NK cells protect against Listeria infection in vivo [56] and are also stimulated by Listeria-in- fected cells in vitro $[57,58]$. The protective effect of NK cells in rats may be related to the relatively large number of Ly49 receptors in rats as compared to mice [59]. The rat MHC-I region is also organized differently from the mouse as described in the next section.

\section{The Rat MHC (RT1) Complex}

The whole genome of the Brown Norway $(\mathrm{BN})$ rat strain was sequenced in 2004 [60]. The $R T 1$ complex of $\mathrm{BN}$ rats consists of $4 \mathrm{Mb}$ and contains at least 220 genes [50]. The MHC-I molecules can be subdivided into classical (Ia) and nonclassical (Ib) molecules. They vary in expression patterns, polymorphisms and functions. The classical MHC molecules are encoded from the RT1-A region in the left flank of the MHC, while the nonclassical ones are encoded from the RT1-CE, RT1-N, RT1-M1, RT1$M 4, R T 1-M 3 A, R T 1-M 3 B$ and $R T 1-M 2$ regions telomeric to the class II/III region (fig. 1) [50]. The centromeric class Ia region (RT1-A) and the first telomeric class $\mathrm{Ib}$ gene cluster (RT1-CE) located on either side of the central MHC class II/III region show the largest degree of homology with the mouse, but $H 2-D / L$ orthologues do not exist in the rat [61]. However, both these regions contain genes that encode ligands for NK cell receptors. The classical RT1-A region contains one, two or three MHC-I genes depending on the haplotype. For instance, the $R T 1^{k}$ and $R T 1^{u}$ haplotypes contain one, $R T 1^{c}$ two and $R T 1^{n}$ three expressed MHC-Ia genes [62-65]. Rat NK cell receptors may show exquisite specificity for certain class I alleles. As an example, the inhibitory rat Ly49i2 NK cell receptor recognizes only one of the RT1-A molecules in the PVG strain $\left(\mathrm{RT} 1-\mathrm{A} 1^{\mathrm{c}}\right)[53,66]$. 
Fig. 2. Schematic presentation of the rat NKC. Note that considerable polymorphisms exist, especially in the Ly49 region, between different rat strains.

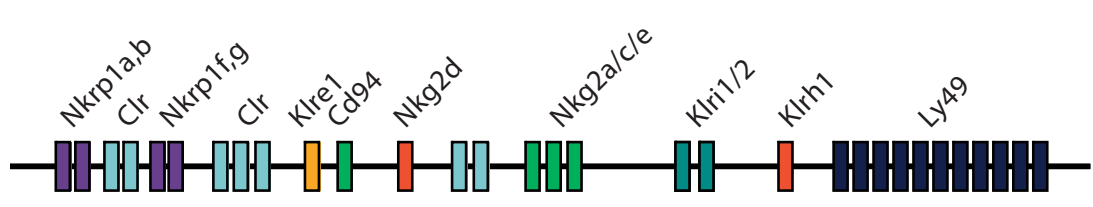

The RT1-CE region contains 16 nonclassical $\mathrm{Ib}$ genes in the $R T 1^{n}$ haplotype $[50,67]$. Thirteen of these are probably expressed [50]. Other haplotypes may express different numbers of RT1-CE genes and molecules, so it is difficult to define alleles within this region. The function of these nonclassical MHC-I molecules has not been well characterized. They are less polymorphic than classical class I molecules and often have a restricted tissue distribution and low surface expression. However, unlike the stress-induced ligands for the NKG2D receptor (MICA in humans and RAE in mice), the RT1-CE molecules are clearly expressed, also on normal unstressed cells like hematopoietic cells. Some RT1-CE molecules can present endogenous peptides recognized by CTLs [68]. Ly49 receptors have been shown to recognize MHC-I-encoded molecules both from the RT1-A and RT1-CE regions [51$55]$. The second telomeric class I gene cluster, $R T 1-N$, also contains 16 class Ib genes in the $\mathrm{BN}$ rat. There are close similarities between the mouse and rat $\mathrm{M}$ region class I genes. The M3 molecule, being orthologous to the mouse $\mathrm{H} 2-\mathrm{M} 3$, probably presents $\mathrm{N}$-formylated peptides to $\mathrm{CD}^{+} \mathrm{T}$ cells; however, its role in resistance to infections in rats remains to be determined. The framework gene mog marks the telomeric border of human leukocyte antigen, but the border of the $R T 1$ complex extends further distally. The class III (also called 'central') region encodes a diverse array of structurally unrelated genes both in mice and rats, including complement factors, TNF, Hsp70 and TAP, many of which are involved in the innate and adaptive immune responses [50].

\section{The NK Cell Gene Complex}

The human, mouse and rat NK cell gene complexes (NKCs) are located on chromosomes 12, 6 and 4, respectively. The murine NKC encodes lectin-like molecules that can be classified into families of highly homologous members. An overview of the rat NKC is depicted in figure 2. These receptors are encoded by clusters of closely linked genes that usually are separated from the other gene families. One exception are the intertwined Nkrp1 and $\mathrm{Clr}$ (C-type lectin related) genes [69]. Between families, the receptors share some general structural features but display limited homology [70]. The rat NKC spans from the Nkrpla to the Ly49i8 gene (fig. 2) [71]. The BN rat NKC contains about 67 killer cell lectin-like receptor genes. Of particular interest is the telomeric region encoding Ly49 receptors. The number of Ly 49 genes differs widely between NKC haplotypes. As a general rule, with reservations about the limited number of rat and mouse strains so far investigated, the rat NKC seems to contain more Ly49 genes than the mouse [59]. As opposed to the mouse, many of these Ly49 receptors contain a charged amino acid in the transmembrane region and are predicted to have an activating function.

\section{Rat Ly49 Receptors Recognize Both Classical and Nonclassical MHC-I Molecules}

In rats, Ly49 receptors recognize both classical and nonclassical MHC-I molecules. Previous studies have suggested that both activating and inhibitory rat Ly 49 receptors recognize polymorphic ligands encoded within the $R T 1-C E$ region [72]. Inhibitory Ly 49 receptors additionally bind MHC-Ia molecules. Based on the genomic sequences of $\mathrm{BN}$ rats, the rat NKC contains 13 inhibitory and 8 activating Ly49 receptors [59]. The Ly49 stimulatory receptor 3 (Ly49s3) was the first activating receptor to be characterized [54]. It recognizes nonclassical MHCI ligands and is present in the high NK alloresponder rat strains PVG and AO, but not in low alloresponder rat strains such as BN and DA. Ly49s3 surface expression is markedly downmodulated in the presence of ligand(s) [73]. The Ly49i5 inhibitory receptor recognizes ligands encoded within the nonclassical class I region of the $R T 1^{u}$ and $R T 1^{l}$ haplotypes, while the structurally related stimulatory Ly49s5 receptor recognizes ligands from the $R T 1^{u}$ haplotype. Ly49s5 is expressed in the high NK alloresponder PVG strain, but not in low alloresponder strains [55]. 


\section{Listeria Infection in Rats - The Role of NK Cells}

Rats depleted of NK cells with the pan-NK monoclonal antibody 3.2.3 towards NKR-P1A (the rat homologue of mouse NKR-P1C) showed increased bacterial loads in the spleen after system administration of the bacterium [56]. Similar observations were made when a subset of NK cells encompassing the majority of Ly 49 receptorbearing cells [56] (termed 'Ly49s $3^{+}$NK cells') $[73,74]$ was depleted. These experiments suggested that NK cells were involved in the resistance to Listeria. Experiments with athymic rats, lacking functional $\mathrm{T}$ cells but with increased number of NK cells [75], further confirmed this finding. These rats resisted Listeria more efficiently than normal rats, i.e. the bacteria had been cleared from the spleen already at day 3 after infection. This was somewhat surprising, since the innate immune system does not induce complete clearance of the bacteria in severely combined immunodeficient mice. However, there are significant differences between mice and rats in the repertoire of Ly49 receptors. Especially the large repertoire of activating Ly49 receptors in PVG rats [54] and the increased frequency of Ly49 receptor-bearing NK cells in athymic nude rats derived from PVG [76] [unpubl. observations] may explain this dichotomy.

The specific role played by Ly49s $3^{+} \mathrm{NK}$ cells in the resistance to Listeria has not yet been pinpointed, but an expansion of this subset in the spleen during Listeria infection has been observed $[24,56]$, which may result from either a local expansion or direct recruitment from other tissues. However, DA rats that lack most Ly49 receptors [77] cleared Listeria as efficiently as did PVG rats [56], suggesting that Ly49-independent resistance mechanisms exist. Other NK cell receptors, such as NKG2D, may contribute by recognizing stress-induced ligands on Listeria-infected cells as shown in mice [78]. That Ly49 receptors are not the sole innate receptors contributing to Listeria resistance was further confirmed in experiments where both Ly49s3 $3^{+}$and Ly49s3 ${ }^{-}$NK cells responded to Listeria-infected cells in vivo with IFN- $\gamma$ production [57].

For further studies of the role of Ly49 receptors in Listeria resistance in vitro, two rat cell lines have been used: $\mathrm{R} 2 \mathrm{M} \phi$ [58] of the $R T 1^{d}$ haplotype and CC531 colon carcinoma epithelial cells ( $R T 1^{u}$ haplotype) [57]. In contrast to normal cells that are easily destroyed by Listeria infection, infection of these lines was easily achievable. In vitro infection of the cells increased the expression of both MHC-Ia and MHC-Ib molecules [57, 58]. This is in contrast to infection with other intracellular pathogens like cytomegalovirus, which either downregulate MHC-I or instruct the infected cell to express 'decoy' MHC-I-like molecules that inhibit NK cells.

In vitro experiments with reporter cell lines, expressing Ly49s5, Ly49s4 or Ly49i4, strongly indicated that increased expression of RT1-CE molecules on infected cells may be detected by Ly49 receptors since blocking with antibodies against RT1-CE-encoded molecules also blocked the interaction with the cognate stimulatory or inhibitory Ly49 receptor [57, 58]. However, since each NK cell expresses several stimulatory and inhibitory NK cell receptors, the overall result of NK cell recognition of a target cell will depend on several NK cell receptor MHCI interactions [79]. The Ly49s4 and Ly49i4 receptors recognize the same ligand(s). Often signals generated by inhibitory NK cell receptors dominate over their stimulatory counterparts. However, if the activating receptors for a given MHC ligand are expressed by different NK cell subsets than their inhibitory counterparts, the chance that activation is overridden by inhibitory receptors is minimized. This is the case for NK cells expressing Ly49s5 and Ly49i5 present on different subpopulations of NK cells [55]. Although it remains to be proven, presumably also Ly49s4 and Ly49i4 may be expressed by different subsets of NK cells. In vitro IFN- $\gamma$ stimulation of CC531 and R2 cells led to increased MHC-I expression and enhanced Ly49 receptor responses similarly to Listeria-infected cells. Taken together, this suggests that the increased receptor response was caused by a general upregulation of MHC-Ib whether induced by Listeria or cytokines.

The upregulation of MHC-I molecules on infected cells both in vitro and in vivo indicates that the in vitro data are relevant for interpretation of the in vivo data. Incubation of bulk spleen mononuclear cells (including NK cells) with Listeria-infected cells (R2 and CC531) induced IFN- $\gamma$ production in NK cells. However, this did not point to an independent role of NK cells, as no IFN- $\gamma$ production was observed in parallel experiments with sorted NK cells. This suggests that other factors are needed for NK cell activation. Apparently, other cells, such as DCs, may be required for NK cell activation and production of IFN- $\gamma$, as has been shown in the mouse. Supernatants from Listeria-infected cells did not induce any IFN$\gamma$ response [57] showing that soluble factors alone were incapable of activating NK cells and that direct contact with accessory cells may be required for IFN- $\gamma$ production by NK cells. It has been suggested that full activation of NK cells requires priming, cytokines and contact with antigen-presenting cells $[28,80]$. 
A general upregulation of MHC-Ib molecules may act as a 'danger' signal for NK cell recognition. IFN- $\gamma$ stimulation of R2 cells or CC531 cells upregulated their MHCI expression similarly to Listeria and also led to increased NK cell receptor responses. Therefore, a general upregulation of nonclassical MHC-I, whether induced by microbial infection or IFN- $\gamma$, was sufficient to explain the results obtained with the reporter cells. However, R2 and CC531 cells do not themselves produce significant amounts of IFN- $\gamma$, suggesting that in vitro infection with Listeria upregulates MHC-I independently of IFN- $\gamma$. The situation may be different in vivo, where bystander cells may produce enough IFN- $\gamma$ for upregulation to occur [55]. The precise role that Ly49 receptor interactions with MHC-I plays in bacterial resistance in vivo also remains to be determined. The depletion experiments with either the pan-NK antibody 3.2.3 or the monoclonal antibody DAR 13 reacting only with the NK cell subset expressing Ly 49 were highly suggestive, but did not prove that Ly49 receptors were instrumental for protection. Experiments investigating the effect of NK cell depletion in rats deficient in Ly49 expressing NK cells still await to be done.

\section{A Novel Role of MHC-Ib in Ly49 Recognition - Future Aspects}

The Listeria model in rats has given the opportunity to gain new knowledge about putative novel functions of nonclassical MHC-I molecules. As already mentioned, expression of stress-induced NKG2D ligands may lead to $\mathrm{T}$ and NK cell activation [81,82]. The upregulation of MHC-Ib molecules on Listeria-infected cells may show some mechanistic similarity to the NKG2D ligands up- regulated during stress or infection and act as 'danger' signals. This is also supported by the fact that MHC-Ib molecules in the rat are usually not targets for CTL responses. Their upregulation during infection may lead to recognition and killing by NK cells expressing the cognate-activating receptor. The mechanism of upregulation is still enigmatic: whether it is only cytokine driven (IFN$\gamma$ ) or might be dependent on more sophisticated mechanisms such as Listeria-derived peptides remains to be determined.

Altogether, data from the rat model suggest that NK cells play an important role in the early defense against Listeria infection. NK cells may directly recognize infected cells through the interaction between Ly49 receptors and their MHC-I ligands, or by other receptors for ligands which are upregulated on Listeria-infected cells. A complex organism like Listeria obviously requires activation of several effector mechanisms of the immune system to be effectively eliminated. NK cell recognition of MHC-Ib molecules on Listeria-infected cells may contribute to the defense at an early stage of the infection. However, it should be kept in mind that activation of resting NK cells may require synergy between multiple receptors present on a single cell [83], and therefore, it would be of interest to investigate if activation of other NK cell receptors like NKG2/CD94, NKG2D and NKp46 is needed for NK cell recognition of infected cells through Ly49 receptors.

Although clinical Listeria infections are relatively rare in the population and present no threat as pandemics, the lessons to be learned from immunity to Listeria may also apply to other intracellular bacteria and give new insight into the multiple mechanisms that the immune system employs to combat such infections.

\section{References}

$\checkmark 1$ Pamer EG: Immune responses to Listeria monocytogenes. Nat Rev Immunol 2004;4: 812-823.

$\checkmark 2$ Freitag NE, Port GC, Miner MD: Listeria monocytogenes - from saprophyte to intracellular pathogen. Nat Rev Microbiol 2009;7: 623-628.

3 Cabanes D, Dehoux P, Dussurget O, Frangeul L, Cossart P: Surface proteins and the pathogenic potential of Listeria monocytogenes. Trends Microbiol 2002;10:238-245.

$\checkmark 4$ Wing E, Gregory S: Listeria monocytogenes: clinical and experimental update. J Infect Dis 2002; 185:S18-S24.
5 Lecuit M: Human listeriosis and animal models. Microbes Infect 2007;9:1216-1225.

-6 Kaufmann SHE: Immunity to intracellular bacteria. Annu Rev Immunol 1993;11:129163.

-7 Neuenhahn M, Kerksiek KM, Nauerth M, Suhre MH, Schiemann M, Gebhardt FE, Stemberger C, Panthel K, Schroder S, Chakraborty T, Jung S, Hochrein H, Russmann H, Brocker T, Busch DH: CD8alpha+ dendritic cells are required for efficient entry of Listeria monocytogenes into the spleen. Immunity 2006;25:619-630.
8 McElroy DS, Ashley TJ, D’Orazio SE: Lymphocytes serve as a reservoir for Listeria monocytogenes growth during infection of mice. Microb Pathog 2009;46:214-221.

9 Schnupf P, Portnoy DA: Listeriolysin O: a phagosome-specific lysin. Microbes Infect 2007;9:1176-1187.

10 Posfay-Barbe KM, Wald ER: Listeriosis. Semin Fetal Neonatal Med 2009;14:228-233.

11 North RJ, Dunn PL, Conlan JW: Murine listeriosis as a model of antimicrobial defense. Immunol Rev 1997;158:27-36.

12 Miki K, Mackanness GB: The passive transfer of acquired resistance to Listeria monocytogenes. J Exp Med 1964;120:93-103. 
$\checkmark 13$ Mackaness GB: Cellular resistance to infection. J Exp Med 1962;116:381-406.

14 Brockstedt DG, Dubensky TW: Promises and challenges for the development of Listeria monocytogenes-based immunotherapies. Expert Rev Vaccines 2008;7:1069-1084.

$\checkmark 15$ Bahjat KS, Prell RA, Allen HE, Liu W, Lemmens EE, Leong ML, Portnoy DA, Dubensky TW Jr, Brockstedt DG, Giedlin MA: Activation of immature hepatic NK cells as immunotherapy for liver metastatic disease. J Immunol 2007;179:7376-7384.

16 Bancroft GJ, Schreiber RD, Unanue ER: Natural immunity: a T-cell-independent pathway of macrophage activation, defined in the SCID mouse. Immunol Rev 1991;124:5-24.

17 Edelson BT, Unanue ER: Immunity to Listeria infection. Immunity 2000;14:503-512.

18 Yin J, Ferguson TA: Identification of an IFN$\gamma$-producing neutrophil early in the response to Listeria monocytogenes. J Immunol 2009; 182:7069-7073.

19 Cousens LP, Wing EJ: Innate defenses in the liver during Listeria infection. Immunol Rev 2000;174:150-159.

-20 Serbina NV, Kuziel W, Flavell R, Akira S, Rollins B, Pamer EG: Sequential MyD88-independent and -dependent activation of innate immune responses to intracellular bacterial infection. Immunity 2003;19:891-901.

$\checkmark 21$ Serbina NV, Salazar-Mather TP, Biron CA, Kuziel WA, Pamer EG: TNF/iNOS-producing dendritic cells mediate innate immune defense against bacterial infection. Immunity 2003;19:59-70.

-22 Kurihara T, Warr G, Loy J, Bravo R: Defects in macrophage recruitment and host defense in mice lacking the CCR2 chemokine receptor. J Exp Med 1997;186:1757-1762.

$\checkmark 23$ Kang SJ, Liang HE, Reizis B, Locksley RM: Regulation of hierarchical clustering and activation of innate immune cells by dendritic cells. Immunity 2008;29:819-833.

24 Shegarfi H, Naper C, Rolstad B, Inngjerdingen M: Listeria monocytogenes infection affects a subset of Ly49-expressing NK cells in the rat. PLoS One 2010;15:e15579.

$\checkmark 25$ Berg RE, Crossley E, Murray S, Forman J: Relative contributions of NK and CD8 T cells to IFN-gamma mediated innate immune protection against Listeria monocytogenes. J Immunol 2005; 175:1751-1757.

-26 Serbina NV, Pamer EG: Coordinating innate immune cells to optimize microbial killing. Immunity 2008;29:672-674.

27 Unanue ER: Studies in listeriosis show the strong symbiosis between the innate cellular system and the T-cell response. Immunol Rev 1997;158:11-25.

28 Humann J, Lenz LL: Activation of naive NK cells in response to Listeria monocytogenes requires IL-18 and contact with infected dendritic cells. J Immunol 2010;184:51725178.
29 Huang S, Hendriks W, Althage A, Hemmi S, Bluethmann H, Kamijo R, Vilcek J, Zinkernagel RM, Aguet M: Immune response in mice that lack the interferon-gamma receptor. Science 1993;259:1742-1745.

30 Carrero JA, Calderon B, Unanue ER: Lymphocytes are detrimental during the early innate immune response against Listeria monocytogenes. J Exp Med 2006;203:933940.

31 O'Connell RM, Saha SK, Vaidya SA, Bruhn KW, Miranda GA, Zarnegar B, Perry AK, Nguyen BO, Lane TF, Taniguchi T, Miller JF, Cheng G: Type I interferon production enhances susceptibility to Listeria monocytogenes infection. J Exp Med 2004;200:437445.

- 32 Auerbuch V, Brockstedt DG, Meyer-Morse N, O’Riordan M, Portnoy DA: Mice lacking the type I interferon receptor are resistant to Listeria monocytogenes. J Exp Med 2004;200: 527-533.

33 Jia T, Leiner I, Dorothee G, Brandl K, Pamer EG: MyD88 and type I interferon receptormediated chemokine induction and monocyte recruitment during Listeria monocytogenes infection. J Immunol 2009;183:12711278.

34 Garcia-Peñarrubia P, Koster FT, Kelley RO, McDowell TD, Bankhurst AD: Antibacterial activity of human natural killer cells. J Exp Med 1989;169:99-113.

35 Bancroft GJ: The role of natural killer cells in innate resistance to infection. Curr Opin Immunol 1993;5:503-510.

36 Lara-Tejero M, Pamer EG: T cell responses to Listeria monocytogenes. Curr Opin Microbiol 2004;7:45-50.

37 D'Orazio SE, Halme DG, Ploegh HL, Starnbach MN: Class Ia MHC-deficient BALB/C mice generate CD8+ T cell-mediated protective immunity against Listeria monocytogenes infection. J Immunol 2003;171:291298.

38 D'Orazio SEF, Shaw CA, Starnbach MN: H2M3-restricted CD8+ T cells are not required for MHC class Ib-restricted immunity against Listeria monocytogenes. J Exp Med 2006;203:383-391.

- 39 Berg RE, Crossley E, Murray S, Forman J: Memory CD8+ $\mathrm{T}$ cells provide innate immune protection against Listeria monocytogenes in the absence of cognate antigen. J Exp Med 2003;198:1583-1593.

-40 Berg RE, Crossley E, Murray S, Forman J: Relative contributions of NK and CD8 T cells to IFN-gamma mediated innate immune protection against Listeria monocytogenes. J Immunol 2005;175:1751-1757.

41 Bancroft GJ, Schreiber RD, Bosma GC, Bosma MJ, Unanue ER: A T cell-independent mechanism of macrophage activation by interferon-gamma. J Immunol 1987; 139:11041107.
42 Hamerman JA, Tchao NK, Lowell CA, Lanier LL: Enhanced Toll-like receptor responses in the absence of signaling adaptor DAP12. Nat Immunol 2005;6:579-586.

43 Lodoen MB, Lanier LL: Natural killer cells as an initial defense against pathogens. Curr Opin Immunol 2006;18:391-398.

44 Teixeira HC, Kaufmann SH: Role of NK1.1+ cells in experimental listeriosis. NK1+ cells are early IFN-gamma producers but impair resistance to Listeria monocytogenes infection. J Immunol 1994;152:1873-1882.

45 Perona-Wright G, Mohrs K, Szaba FM, Kummer LW, Madan R, Karp CL, Johnson LL, Smiley ST, Mohrs M: Systemic but not local infections elicit immunosuppressive IL-10 production by natural killer cells. Cell Host Microbe 2009;6:503-512.

46 Vivier E, Ugolini S: Regulatory natural killer cells: new players in the IL-10 anti-inflammatory response. Cell Host Microbe 2009;6: 493-495.

47 Lecuit M, Dramsi S, Gottardi C, Fedor-Chaiken M, Gumbiner B, Cossart P: A single amino acid in E-cadherin responsible for host specificity towards the human pathogen Listeria monocytogenes. EMBO J 1999;18:39563963.

48 Jungi TW, Kunz HW, Gill TJ III, Jungi R: Genetic control of cell-mediated immunity in the rat. 2. Sharing of either the RT1.A or RT1.B locus is sufficient for transfer of antimicrobial resistance. J Immunogenet 1982;9: 433-443.

-49 Ioannidu S, Walter L, Dressel R, Gunther E: Physical map and expression profile of genes of the telomeric class I gene region of the rat MHC. J Immunol 2001;166:3957-3965.

50 Hurt P, Walter L, Sudbrak R, Klages S, Muller I, Shiina T, Inoko H, Lehrach H, Gunther E, Reinhardt R, Himmelbauer H: The genomic sequence and comparative analysis of the rat major histocompatibility complex. Genome Res 2004;14:631-639.

51 Naper C, Ryan JC, Kirsch R, Butcher GW, Rolstad B, Vaage JT: Genes in two major histocompatibility complex class I regions control selection, phenotype, and function of a rat Ly-49 natural killer cell subset. Eur J Immunol 1999;29:2046-2053.

52 Rolstad B, Naper C, Lovik G, Vaage JT, Ryan JC, Backman-Petersson E, Kirsch RD, Butcher GW: Rat natural killer cell receptor systems and recognition of MHC class I molecules. Immunol Rev 2001;181:149-157.

53 Naper C, Hayashi S, Joly E, Butcher GW, Rolstad B, Vaage JT, Ryan JC: Ly49i2 is an inhibitory rat natural killer cell receptor for an MHC class Ia molecule (RT1-A1c). Eur J Immunol 2002;32:2031-2036.

54 Naper C, Hayashi S, Kveberg L, Niemi EC, Lanier LL, Vaage JT, Ryan JC: Ly-49s3 is a promiscuous activating rat $\mathrm{NK}$ cell receptor for nonclassical MHC class I-encoded target ligands. J Immunol 2002;169:22-30. 
-55 Naper C, Dai KZ, Kveberg L, Rolstad B, Niemi EC, Vaage JT, Ryan JC: Two structurally related rat Ly49 receptors with opposing functions (Ly49 stimulatory receptor 5 and Ly49 inhibitory receptor 5) recognize nonclassical MHC class Ib-encoded target ligands. J Immunol 2005;174:2702-2711.

-56 Shegarfi H, Sydnes K, Lovik M, Inngjerdingen M, Rolstad B, Naper C: The role of natural killer cells in resistance to the intracellular bacterium Listeria monocytogenes in rats. Scand J Immunol 2009;70:238-244.

-57 Shegarfi H, Dai KZ, Inngjerdingen M, Ryan JC, Vaage JT, Rolstad B, Naper C: The activating rat Ly49s5 receptor responds to increased levels of MHC class Ib molecules on Listeria monocytogenes-infected enteric epithelial cells. Eur J Immunol 2010;40:3535 3543.

58 Shegarfi H, Dai K-Z, Daws MR, Ryan JC, Vaage JT, Naper C, Rolstad B: The rat NK cell receptors Ly49s4 and Ly49i4 recognize MHC class I molecules on Listeria monocytogenes infected R2 macrophages. J Leukoc Biol 2011, Epub ahead of print.

59 Nylenna O, Naper C, Vaage JT, Woon PY, Gauguier D, Dissen E, Ryan JC, Fossum S: The genes and gene organization of the Ly49 region of the rat natural killer cell gene complex. Eur J Immunol 2005;35:261-272.

-60 Genome sequence of the Brown Norway rat yields insights into mammalian evolution. Nature 2004;428:493-521.

61 Gunther E, Walter L: The major histocompatibility complex of the rat (Rattus norvegicus). Immunogenetics 2001;53:520-542.

62 Gonzalez-Munoz AL, Le Rolle AF, Brun H, Hedrich HJ, Wedekind D, Powis SJ, Joly E, Butcher GW: A novel instance of class I modification (CIM) affecting two of three rat class I RT1-A molecules within one MHC haplotype. J Immunol 2003;171:274-284.

63 Joly E, Clarkson C, Howard JC, Butcher GW: Isolation of a functional cDNA encoding the RT1.Au MHC class I heavy chain by a novel PCR-based method. Immunogenetics 1995; 41:326-328.
64 Joly E, Leong L, Coadwell WJ, Clarkson C, Butcher GW: The rat MHC haplotype $R T 1^{c}$ expresses two classical class I molecules. J Immunol 1996;157:1551-1558.

65 Walter L, Gunther E: Physical mapping and evolution of the centromeric class I genecontaining region of the rat MHC. Immunogenetics 2000;51:829-837.

66 Naper C, Hayashi S, Joly E, Butcher GW, Rolstad B, Vaage JT, Ryan JC: Ly49i2 is an inhibitory rat natural killer cell receptor for an MHC class Ia molecule (RT1-A1c). Eur J Immunol 2002;32:2031-2036.

67 Roos C, Walter L: Considerable haplotypic diversity in the RT1-CE class I gene region of the rat major histocompatibility complex. Immunogenetics 2005;56:773-777.

68 Leong L, Le Rolle AM, Deverson EV, Powis $\mathrm{SH}$, Larkins AP, Vaage JT, Stokland AA, Lambracht-Washington D, Rolstad B, Joly E, Butcher GW: RT1.U: identification of a novel active class Ib alloantigen of the rat MHC. J Immunol 1999;162:743-752.

-69 Kveberg L, Dai KZ, Westgaard IH, Daws MR, Fossum S, Naper C, Vaage JT: Two major groups of rat NKR-P1 receptors can be distinguished based on chromosomal localization, phylogenetic analysis and Clr ligand binding. Eur J Immunol 2009;39:541-551.

70 Yokoyama WM, Plougastel BFM: Immune functions encoded by the natural killer gene complex. Nat Rev Immunol 2003;3:304-316.

71 Flornes LM, Nylenna O, Saether PC, Daws MR, Dissen E, Fossum S: The complete inventory of receptors encoded by the rat natural killer cell gene complex. Immunogenetics 2010;62:521-530.

72 Naper C, Vaage JT, Lambracht D, Løvik G, Butcher GW, Wonigeit K, Rolstad B: Alloreactive natural killer cells in the rat. Complex genetics of MHC control. Eur J Immunol 1995;25:1249-1256.

73 Kveberg L, Back CJ, Dai KZ, Inngjerdingen M, Rolstad B, Ryan JC, Vaage JT, Naper C: The novel inhibitory NKR-P1C receptor and Ly49s3 identify two complementary, functionally distinct NK cell subsets in rats. J Immunol 2006;176:4133-4140.
74 Kveberg L, Dai KZ, Dissen E, Ryan JC, Rolstad B, Vaage JT, Naper C: Strain-dependent expression of four structurally related rat Ly49 receptors; correlation with NK gene complex haplotype and NK alloreactivity. Immunogenetics 2006;58:905-916.

-75 Reynolds CW, Timonen T, Holden HT, Hansen CT, Herberman RB: Natural killer cell activity in the rat. Analysis of effector cell morphology and effects of interferon on natural killer cell function in the athymic (nude) rat. Eur J Immunol 1982;12:577-582.

76 Tønnesen B, Rolstad B: In vivo elimination of allogeneic lymphocytes in normal and T-celldeficient rats. Elimination does not require T cells. Scand J Immunol 1983;17:303-312.

77 Dissen E, Ryan JC, Seaman WE, Fossum S: An autosomal dominant locus, Nka, mapping to the Ly-49 region of a rat natural killer (NK) gene complex, controls NK cell lysis of allogeneic lymphocytes. J Exp Med 1996; 183:2197-2207.

78 Hamerman JA, Ogasawara K, Lanier LL: Cutting edge: Toll-like receptor signaling in macrophages induces ligands for the NKG2D receptor. J Immunol 2004;172:2001-2005.

-79 Raulet DH, Guerra N: Oncogenic stress sensed by the immune system: role of natural killer cell receptors. Nat Rev Immunol 2009; 9:568-580.

80 Lucas M, Schachterle W, Oberle K, Aichele P, Diefenbach A: Dendritic cells prime natural killer cells by trans-presenting interleukin 15. Immunity 2007;26:503-517.

-81 Bauer S, Groh V, Wu J, Steinle A, Phillips JH Lanier LL, Spies T: Activation of NK cells and T cells by NKG2D, a receptor for stress-inducible MICA. Science 1999;285:727-729.

- 82 Cerwenka A, Bakker AB, McClanahan T, Wagner J, Wu J, Phillips JH, Lanier LL: Retinoic acid early inducible genes define a ligand family for the activating NKG2D receptor in mice. Immunity 2000;12:721-727.

83 Bryceson YT, March ME, Ljunggren HG, Long EO: Synergy among receptors on resting NK cells for the activation of natural cytotoxicity and cytokine secretion. Blood 2006;107:159-166. 